\title{
BIOLOGIA DE ATEUCHUS MUTILATUS HAROLD, 1867 *
}

\section{BIOLOGY OF ATEUCHUS MUTILATUS HAROLD. 1867}

\author{
ILONA VIVIAN KLEEMANN STUMPF ** \\ ENNIO LUZ :**: * \\ VALDIR ROBERTO TONIN ****
}

RECEBIDO EM 03/09/86

APROVADO EM 09/09/86

\section{INTRODUÇĀO}

Estudamos o comportamento de Ateuchus mutilatus Harold, 1867 no campo e no laboratório.

Realizamos o levantamento através de armadilhas com isca: alimento (fezes de porco) e de criadouros (fezes de bovinos, de eqüinos, de ovinos e de suínos).

A ocorrência isolada e sintópica em armadithas e criadouros também foi estudada.

Experimentalmente, observamos vários aspectos da biologia de Ateuchus mutilatus como: ovo, larva de primeiro e de terceiro estádio, pupa, adulto, sobrevivência do adulto, atividade, nidificação e preferência alimentar.

\section{MATERIAL E MÉTODOS}

As coletas foram realizadas semanalmente, durante o período de outubro de 1983 a outubro de 1984, em Mandirituba, a cerca de $35 \mathrm{~km}$ de Curitiba, Estado do Paraná, situando-se entre as latitudes $25^{\circ} 30^{\prime}-25^{\circ} 45^{\prime} \mathrm{S}$ e as longitudes $49^{\circ} 15^{\circ}-$ $49^{\circ} 30^{\prime} \mathrm{W}$. (Figura 1).

* Tese de Doutorado em Entomologia apresentada no Departamento de Zoologia do Setor de Ciências Biológicas da Univerşidade Federal do Paraná.

* Protessora Adjunta do Departamento de Clências Fisiológicas, do Setor de Ciências Biológicas da Universidade Federal do Paraná.

*** Professor Titular do Departamento de Patologia Básica, do Setor de Giências Biológicas da Universidade Federal do Paraná.

* Médica-Veterifário da Sociedade Hípica Paranaense. 
156

Acta Biol. Par., Curitiba, 15(1,2,3,4):155-177, 1986

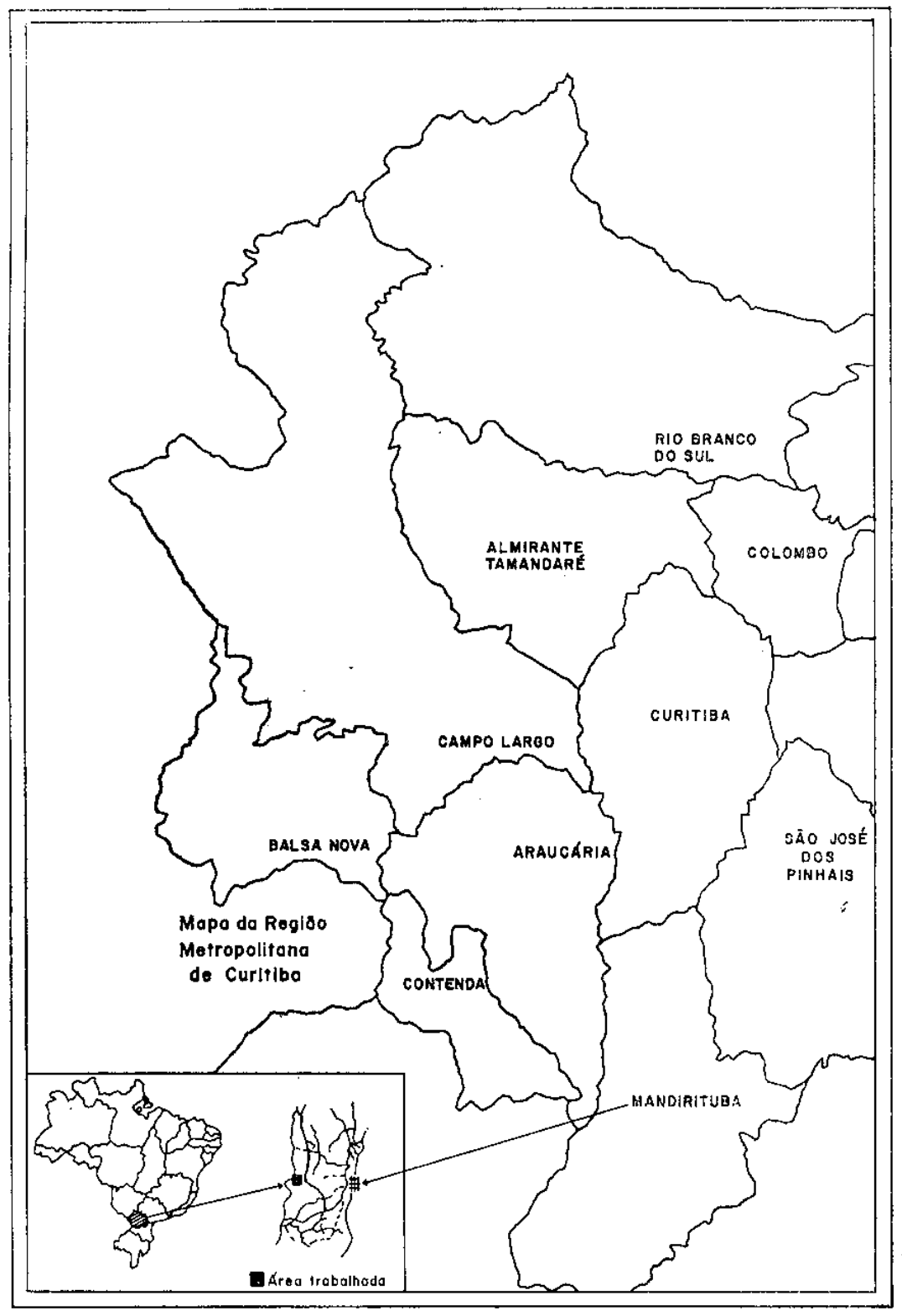

Figura 1 Mapa da Região Metropolitana de Curitiba. 
Os copríneos foram coletados no período das 7 às 12 horas. A área trabalhada foi de aproximadamente $6 \mathrm{~km}^{2}$.

Estabelecemos 15 armadilhas, cujos locais foram escolhidos segundo três tipos de luminosidade: a) locais ensolarados; b) locais parcialmente sombreados; c) locais sombreados.

Cada armadilha consistia de duas latas superpostas, soldadas entre si, tendo, como separação, uma tela de arame milimétrica. A armaditha era enterrada no solo e a tela ficava ao nível do mesmo. Na tela colocávamos fezes recentes de porco e coletávamos semanalmente os copríneos ali existentes.

Os criadouros constituídos de deposição natural de fezes de bovinos, eqüinos, ovinos e suínos eram também pesquisados semanalmente. Essa pesquisa era feita com a retirada de todo - bolo fecal e a observação da existência de orifícios na terra, que indicavam a presença de copríneos nidificando. Acompanhando os orifícios que apareciam na superfície, realizamos cortes verticais no solo, observando o trajeto, a profundidade, o tamanho e a forma da massa fecal utilizada pelos copríneos. Con o auxilio de uma "cortadeira" e de uma espátula metálica, iniciávamos a escavação, com a captura dos coprineos adultos, das larvas e dos ovos.

Os ovos coletados no campo eram trazidos para o laboratório, dentro da câmara do ovo, colocados em frascos preenchidos com fezes de eqüinos. Estes frascos eram colocados dentro de una caixa de isopor. As observações eram realizadas de 10 em 10 dias e a temperatura observada diariamente. Estudamos a sobrevivência de 10 exemplares adultos de Ateuchus mutilatus em laboratório, com a duração de três meses, sendo a temperatura tomada diariamente.

Para verificarmos a atividade do Ateuchus mutilatus colocávamos bolos de massa fecal de eqüinos, no solo, às 6 horas da manhã. Às 18 hol as examinávamos as fezes à procura de copríneos, e os retirava quando existentes. No dia seguinte, às 6 horas, procediamos da mesma forma.

\section{RESULTADOS E DISCUSSÕES}

1) Densidade geral: Dos 4.869 escarabeídeos capturados, 323 eram Ateuchus mutilatus $(6,60 \%)$. O major número de exemplares capturados ocorreu em 1984, nos meses de outubro (68), março (48), maio (45) e abril (32). (Tabela I e figura 2). 


\section{TABEL $\perp$ A}

Resultados das capturas mensais de Ateuchus muálatus Harold, 1867, em criadouros e armadilhas, em Mandirituba, PR, no período de outubro de 1983 a outubro de 1984 .

\begin{tabular}{|c|c|c|c|c|c|c|c|c|c|c|c|c|}
\hline \multirow[b]{2}{*}{ Mês } & \multicolumn{6}{|c|}{ CRIADOUROS } & \multicolumn{6}{|c|}{ A R MADILHAS } \\
\hline & 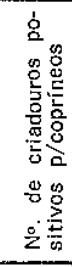 & 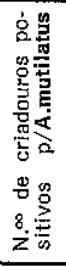 & 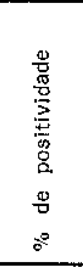 & 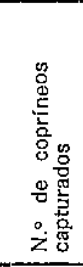 & 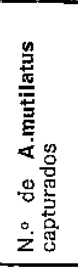 & 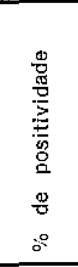 & 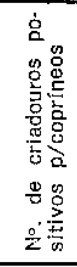 & 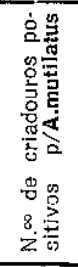 & 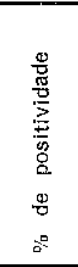 & 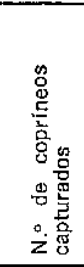 & 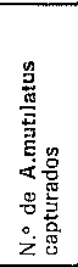 & 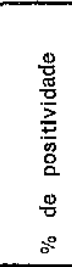 \\
\hline Out. & 6 & . & & 12 & & & 20 & . & & 171 & .. & $\cdots$ \\
\hline Nov. & 36 & 3 & 8,3 & 212 & 6 & 2,8 & 37 & 5 & 13,5 & 222 & 11 & 4,9 \\
\hline Dez. & 32 & 5 & 15,6 & 169 & 10 & 5,9 & 37 & 2 & 5,4 & 362 & 5 & 1,4 \\
\hline Jan. & 36 & 3 & 8,3 & 328 & 9 & 2,7 & 47 & 3 & 6,4 & 334 & 9 & 2,7 \\
\hline Fev. & 41 & 3 & 7,3 & 118 & 8 & 6,8 & 32 & 3 & 9,4 & 107 & 7 & 6,5 \\
\hline Mar. & 63 & 12 & 19,0 & 385 & 35 & 9,1 & 29 & 4 & 13,8 & 175 & 13 & 7,4 \\
\hline Abril & 63 & 11 & 17,5 & 249 & 28 & 11,2 & 22 & 2 & 9,1 & 101 & 4 & 4,0 \\
\hline Maio & 70 & 10 & 114,3 & 170 & 35 & 20,6 & 20 & 6 & 30,0 & 37 & 10 & 27,0 \\
\hline Jun. & 45 & 9 & 20,0 & 131 & 16 & 12,2 & 17 & 3 & 17,6 & 66 & 3 & 4,5 \\
\hline Jual. & 47 & 3 & 6,4 & 164 & 8 & 4,9 & 14 & 5 & 35,7 & 186 & 9 & 4,8 \\
\hline Ago. & 43 & 4 & 9,3 & 111 & 11 & 9,9 & 7 & 2 & 28,6 & 9 & 2 & 22,2 \\
\hline Set. & 66 & 11 & 116.7 & 282 & 16 & 5,7 & 11 & $\ldots$ & $\ldots$ & 29 & . & $\ldots$ \\
\hline Out. & 113 & 21 & 18,6 & 644 & 64 & 9,9 & 18 & 2 & 111,1 & 115 & 4 & 3,5 \\
\hline 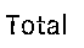 & 661 & 95 & 14,4 & 2975 & 246 & 8,3 & 311 & 37 & 11,9 & 1914 & 77 & 4,0 \\
\hline
\end{tabular}




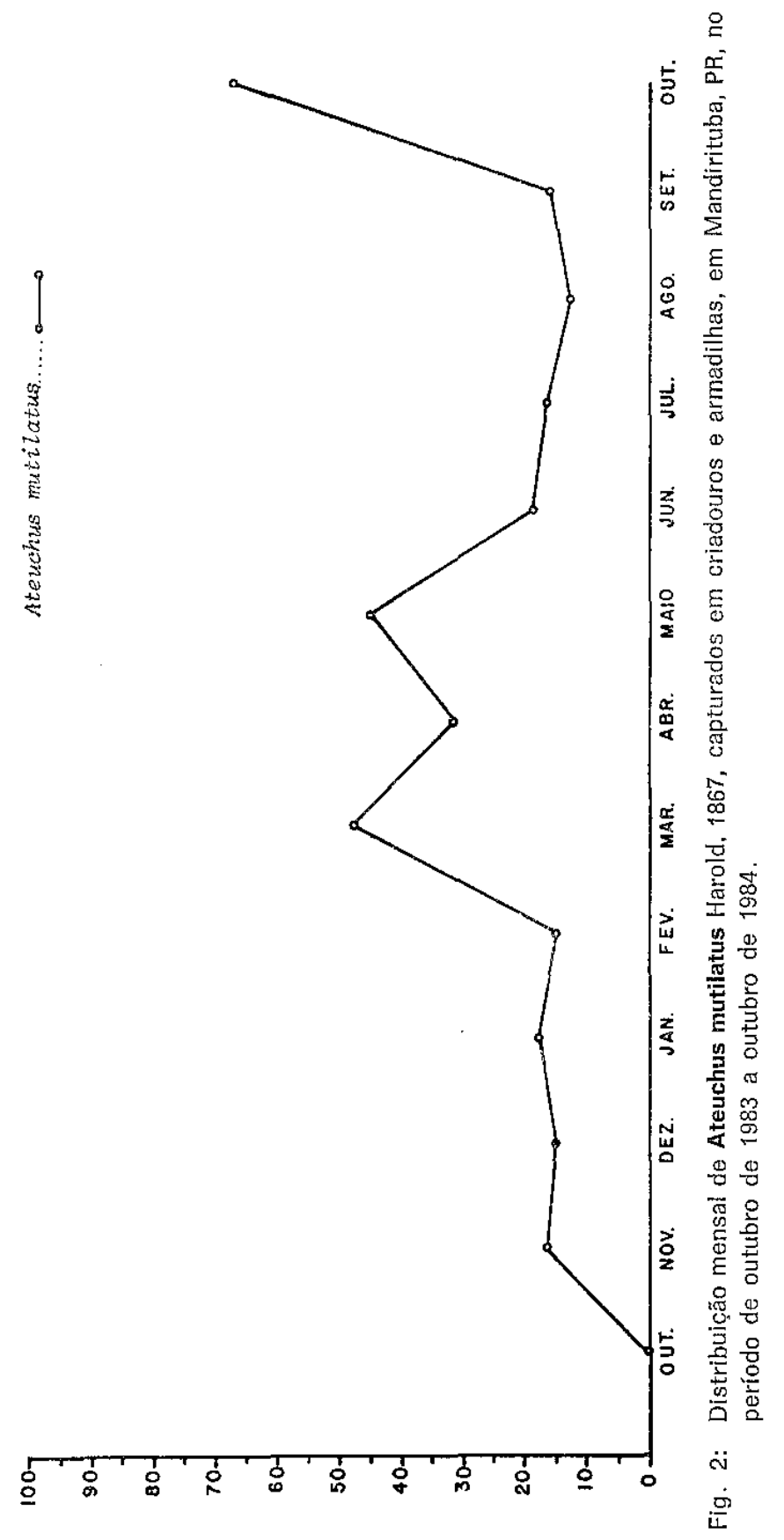


a) Criadouros: 0 índice geral para esse tipo de captura foi de $8,3 \%$ dos 2.975 copríneos. A maior densidade da espécie ocorreu em 1984, nos meses como segue: maio $(20,6 \%)$, junho $(12,2 \%)$, abril $(11,2 \%)$, agosto e outubro $(9,9 \%)$, e marco $(9,1 \%)$. (Tabela 1). Dos 661 criadouros positivos para copríneos, $14,4 \%$ eram para Arenchus mutilatus (95 criadouros). Os meses do ano de 1984 de major número de criadouros para a espécie forcm: junho $(20,0 \%)$, marco $(19,0 \%)$, outubro $[18,6 \%)$, e abril $(17,5 \%)$. (Tabela 1$)$

b) Pref́erência alimentar e nidificação: Observamos que há uma nítida preferencia pelo Ateuchus mutilatus na procura de fezes de eqüinos $(75,2 \%)$; em seguida, fezes de suínos $(13,0 \%)$ e fezes de bovinos $(11,8 \%)$. Nas fezes de ovinos, não foi encontrado nenhum exemplar. (Tabela ll e figua 3). Na tabela III vemos que o maior número de exemplares foi encontrado nidificando em fezes de eqüinos em 1984, nos meses de outubro (61), março (30) e maio (20). Negativo em outubro de 1983. Has fezes de suínos, no mês de maio de 1984, encontramos nove exemplares de Ateuchus mutilatus e, no mês de junho do mesmo ano, oito. Negativo nos meses de outubro de 1983, e janeiro, fevereiro, julho, agosto e outubro de 1984. (Tabela IV). Já nas fezes de bovinos, os meses com maior número de exemplares form: janeiro e abril de 1984 com seis. Em outubro e novembro de 1983 , e julho e agosto de 1984, não foram encontrados. [Tabela V).

c) Armadilhas: Das 311 armadilhas com escarabeídeos, $11,9 \%$ eram para Aterchess nuthlatus, com 37 armadilhas positivas. A freqüencia maior deu-se nos meses de julho $(35,7 \%)$, maio $(30,0 \%$ ) e agosto $(28,6 \%)$, em 1984 . Nos meses de outubro de 1983 e setembro de 1984, não encontramos nenhuma armadilha com essa espécie. (Tabela I). De 1.914 escarabeídeos capturados, foram obtidos $4,0 \%$ como índice geral nas armadilhas. Nos meses de maio $(27,0 \%)$ e em agosto $[22,2 \%)$, em 1934 , encontramos a maior percentagem dessa espécie em armadilhas em relação aos copríneos. Nos meses de outubro de 1983 e setambro de 1984, não encontramos qualquer exemplar. [Tabela I).

Na tabela VI e na figura 4, não observamos diferencas com relação à luminosidade, uma vez que a distribuição dessa espécie foi uniforme. Encontramos exemplares dessa espécie nas armadilhas parcialmente sombreadas (36), nas ensolaradas (22) e nas sombreadas (19); isso se deu, provavelmente, devido a sua atividade ser noturna, conforme nossas observações. 


\section{TABELA I]}

Distribuição por tipo de criadouros, de Ateuchus mutilatus Harold, 1867, capturados em Mandirituba, PR, no período de outubro de 1983 a outubro de 1984.

\begin{tabular}{|c|c|c|c|c|c|c|c|c|}
\hline \multicolumn{2}{|c|}{$\begin{array}{c}\text { Fezes de } \\
\text { bovinos }\end{array}$} & \multicolumn{2}{|c|}{$\begin{array}{c}\text { Fezes de } \\
\text { equînos }\end{array}$} & \multicolumn{2}{|c|}{$\begin{array}{l}\text { Fezes de } \\
\text { ovinos }\end{array}$} & \multicolumn{2}{|c|}{$\begin{array}{l}\text { Fezes de } \\
\text { suínos }\end{array}$} & \multirow{2}{*}{ Tota } \\
\hline $\begin{array}{l}\text { Exem- } \\
\text { plar }\end{array}$ & $\%$ & $\begin{array}{c}\text { Exem- } \\
\text { plar }\end{array}$ & $\%$ & $\begin{array}{l}\text { Exem- } \\
\text { plar }\end{array}$ & $\%$ & $\begin{array}{c}\text { Exem- } \\
\text { plar }\end{array}$ & $\%$ & \\
\hline 29 & 11,8 & 185 & 75,2 & $\ldots$ & $\ldots$ & 32 & 13,0 & 264 \\
\hline
\end{tabular}




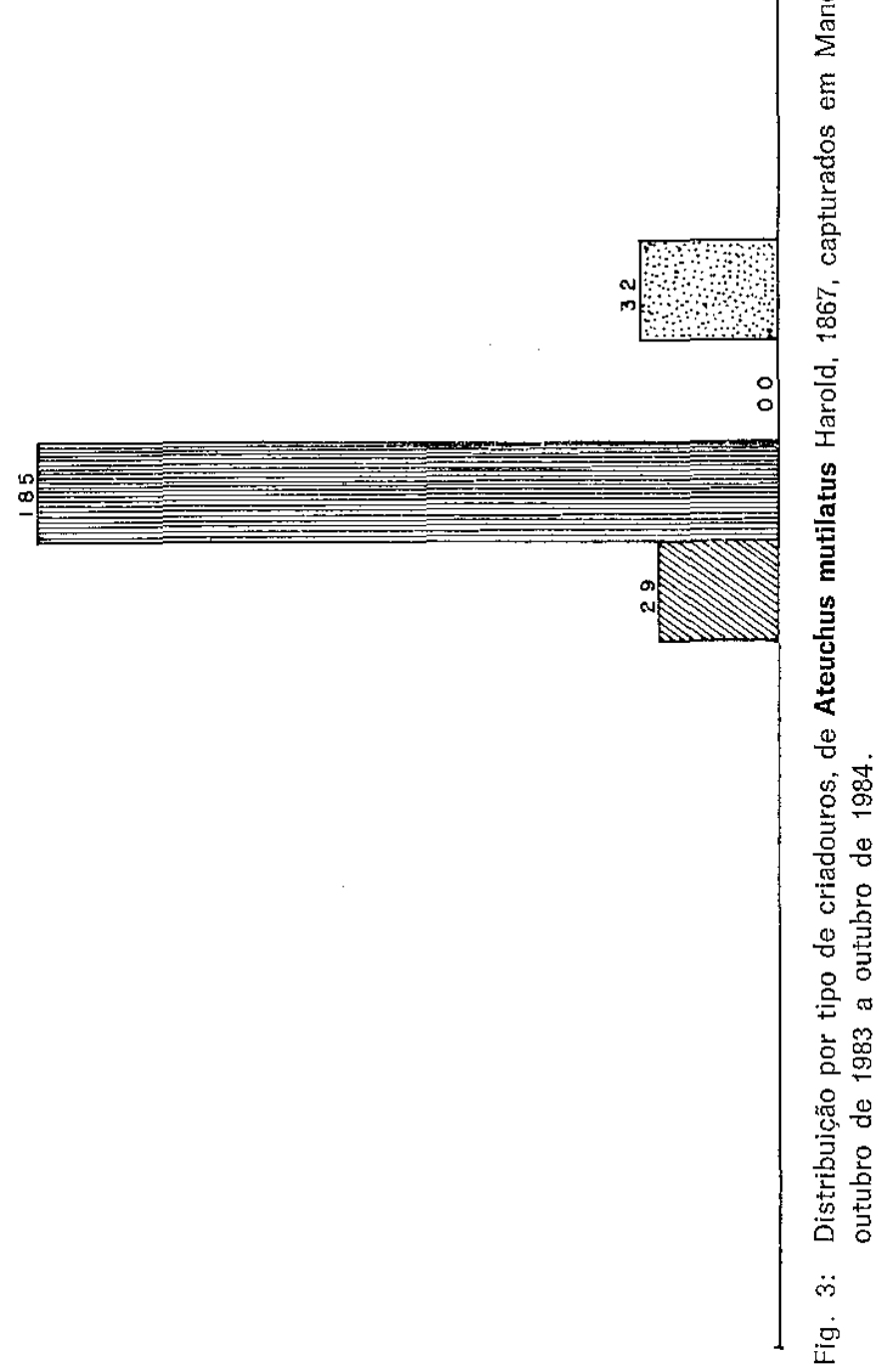


TABELA III

Distribuição mensal de Ateuchus mutilatus Harold, 1867, capturados em criadouros (fezes de eqüinos), em Mandirituba, PR, no período de outubro de 1983 a outubro de 1984 .

\begin{tabular}{|c|c|c|c|c|c|}
\hline Meses & $\begin{array}{l}\text { N.o de } \\
\text { criadouros } \\
\text { resquisados }\end{array}$ & $\begin{array}{l}\text { N. de } \\
\text { criadouros } \\
\text { positivos }\end{array}$ & $\begin{array}{c}\% \text { de } \\
\text { positividaje }\end{array}$ & $\begin{array}{l}\text { N.o de } \\
\text { exemplares } \\
\text { capturados }\end{array}$ & $\begin{array}{l}\text { N.o de } \\
\text { Ateuchus mutilatus } \\
\text { capturados }\end{array}$ \\
\hline $\begin{array}{l}\text { Outubro } \\
\text { Novembro } \\
\text { Dezembro } \\
\text { Janeiro } \\
\text { Fevereiro } \\
\text { Março } \\
\text { Abril } \\
\text { Majo } \\
\text { Junho } \\
\text { Julho } \\
\text { Agosto } \\
\text { Setembro } \\
\text { Outubro }\end{array}$ & $\begin{array}{r}50 \\
66 \\
40 \\
18 \\
21 \\
49 \\
36 \\
86 \\
75 \\
116 \\
86 \\
57 \\
76 \\
\end{array}$ & $\begin{array}{l}12 \\
12 \\
13 \\
18 \\
21 \\
29 \\
24 \\
46 \\
33 \\
25 \\
15 \\
27 \\
44 \\
\end{array}$ & $\begin{array}{r}18,2 \\
32,5 \\
100,0 \\
100,0 \\
59,2 \\
66,7 \\
53,5 \\
44,0 \\
21,5 \\
17,4 \\
47,3 \\
57.9\end{array}$ & $\begin{array}{r}57 \\
92 \\
158 \\
50 \\
125 \\
97 \\
114 \\
77 \\
69 \\
47 \\
113 \\
350 \\
\end{array}$ & $\begin{array}{r}3 \\
5 \\
3 \\
6 \\
30 \\
19 \\
25 \\
5 \\
8 \\
11 \\
9 \\
61 \\
\end{array}$ \\
\hline Total & 776 & 307 & 39,6 & 1349 & 185 \\
\hline
\end{tabular}

TABELA IV

Distribuição mensal de Ateuchus mutilatus Harold, 1867, capturados em criadouros (fezes de suínos), em Mandirituba, PR, no período de outubro de 1993 a outubro de 1984.

\begin{tabular}{|c|c|c|c|c|c|}
\hline Meses & $\begin{array}{l}\text { N.o de } \\
\text { rriadouras } \\
\text { esquisados }\end{array}$ & $\begin{array}{l}\text { N. de } \\
\text { criadouros } \\
\text { positivos }\end{array}$ & $\begin{array}{l}\% \text { de } \\
\text { positividade }\end{array}$ & $\begin{array}{l}\text { N. de } \\
\text { exemplares } \\
\text { capturados }\end{array}$ & $\begin{array}{l}\mathrm{N}^{\circ} \text { de } \\
\text { Ateuchus mutilatus } \\
\text { Capturados }\end{array}$ \\
\hline Outubro & 51 & 6 & 11,8 & 12 & . \\
\hline Novembro & 65 & 26 & 40,0 & 149 & 3 \\
\hline Dezembro & 38 & 12 & 31,6 & 66 & 3 \\
\hline Janeiro & 14 & 14 & 100,0 & 133 & $\ldots$ \\
\hline Fevereiro & 12 & 9 & 75,0 & 43 & $\cdots$ \\
\hline Março & 32 & 24 & 75,0 & 243 & 2 \\
\hline Abril & 23 & 19 & 72,6 & 100 & 3 \\
\hline Majo & 49 & 18 & 36,7 & 48 & 9 \\
\hline Junho & 38 & 10 & 26,3 & 49 & 8 \\
\hline Julho & 95 & 17 & 17,9 & 74 & $\cdots$ \\
\hline Agosto & 84 & 27 & 32,1 & 59 & $\ldots$ \\
\hline Setembro & 71 & 31 & 43,7 & 84 & 4 \\
\hline Outubro & 99 & 53 & 53,5 & 248 & $\ldots$ \\
\hline Tot a I & 671 & 266 & 39,6 & 1308 & 32 \\
\hline
\end{tabular}




\section{TABELA $V$}

Distribuição mensal de Ateuchus mutilatus Harold, 1867, capturados em criadouros (fezes de bovinos), em Mandirituba, PR, no períoda de outubro de 1983 a outubro de 1984

\begin{tabular}{l|ccccc}
\hline Meses & $\begin{array}{c}\text { Nods } \\
\text { rriadouros } \\
\text { sesquisados }\end{array}$ & $\begin{array}{c}\text { Node } \\
\text { criadouros } \\
\text { positivos }\end{array}$ & $\begin{array}{c}\text { No de } \\
\text { positividade }\end{array}$ & $\begin{array}{c}\text { No de } \\
\text { exemplares } \\
\text { capturados }\end{array}$ & $\begin{array}{c}\text { Asenchus mutilatus } \\
\text { capturados }\end{array}$ \\
\hline Outubro & 13 & $\ldots$ & $\ldots$ & $\ldots$ & $\ldots$ \\
Novembro & 57 & 1 & 1,7 & 6 & $\ldots$ \\
Dezembro & 43 & 6 & 13,9 & 9 & 2 \\
Janeiro & 4 & 1 & 25,0 & 34 & 6 \\
Fevereiro & 10 & 8 & 80,0 & 13 & 2 \\
Marco & 32 & 6 & 18,7 & 12 & 3 \\
Abril & 42 & 18 & 42,8 & 49 & 6 \\
Maio & 37 & 6 & 16,2 & 8 & 1 \\
Junho & 16 & 2 & 12,5 & 5 & 3 \\
Julho & 53 & 3 & 5,7 & 19 & $\ldots$ \\
Agosto & 38 & 1 & 2,6 & 5 & $\ldots$ \\
Setembro & 23 & 4 & 17,4 & 81 & 3 \\
Outubro & 44 & 9 & 20,4 & 36 & 3 \\
\hline To t a & 412 & 65 & 15,8 & 277 & 29 \\
\hline
\end{tabular}

\section{TABELA VI}

Distribuição mensal de Ateuchus mutilatus Harold, 1867, capturados em armadilhas ensolaradas, parcialmente sombreadas e sombreadas, em Mandirituba, PR, no período de outubro de 1983 a outubro de 1984.

\begin{tabular}{|c|c|c|c|c|c|c|c|}
\hline \multirow{2}{*}{$\begin{array}{c}\text { Armadi- } \\
\text { thas }\end{array}$} & \multicolumn{2}{|c|}{ Sombreadas } & \multicolumn{2}{|c|}{$\begin{array}{c}\text { Parcialmente } \\
\text { Sombreadas }\end{array}$} & \multicolumn{2}{|c|}{ Ensolaradas } & \multirow{2}{*}{ Total } \\
\hline & Exemplar & $\%$ & Exemplar & $\%$ & Exemplar & $\%$ & \\
\hline & 19 & 24,7 & 36 & 46,8 & 22 & 28,5 & 77 \\
\hline
\end{tabular}




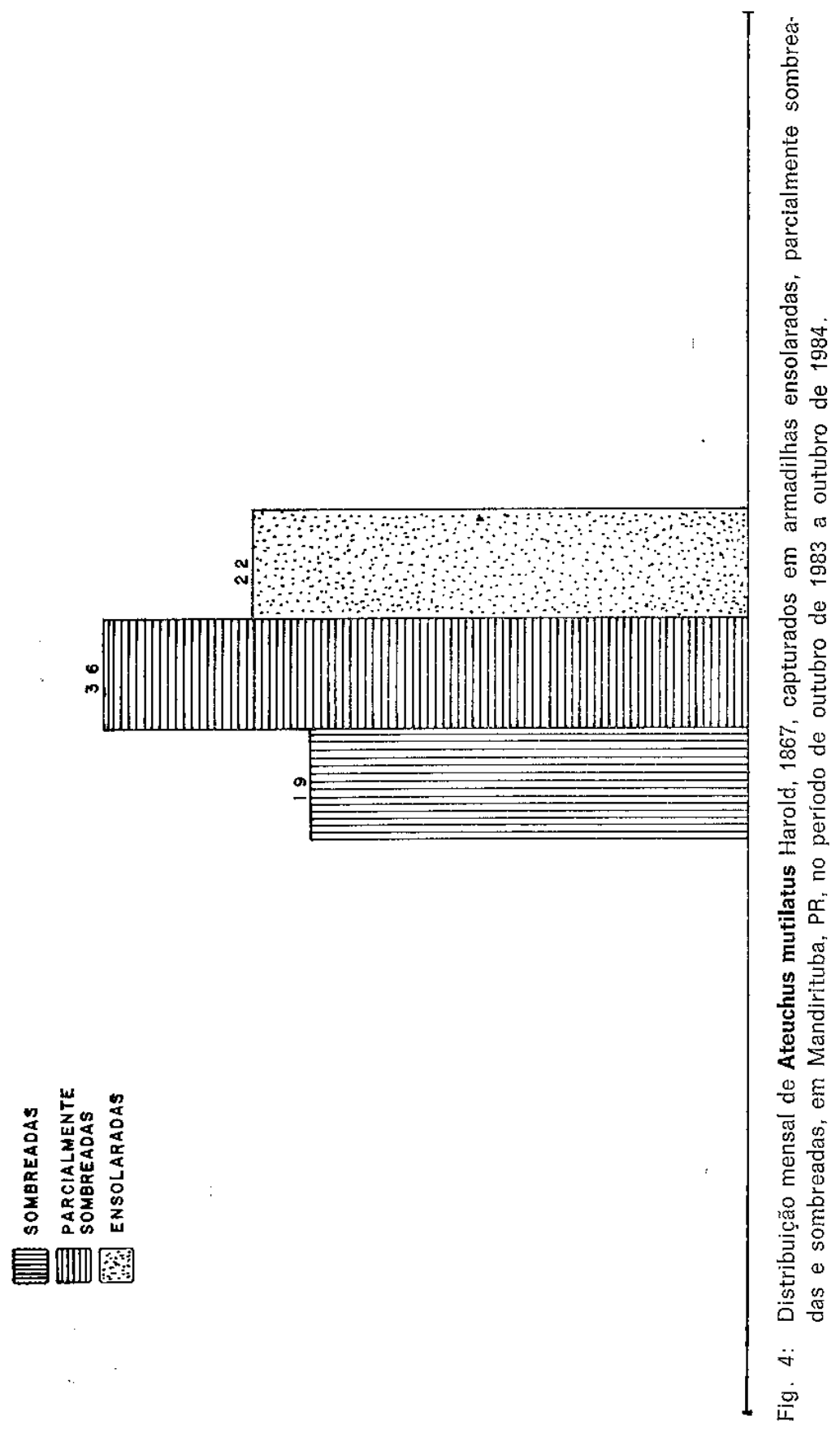


d) Atividade e sobrevivência: Observamos na tabela Vil, que dos 48 copríneos capturados durante a noite, nove eram Ateuches mutilatus. No mês de março foi registrada a captura de dois copríneos, enquanto que nos outros meses registrou-se a preesnça de um único exemplar. Os meses de novembro de 1983, janeiro, junho e agosto de 1984, apresentaram-se negativos para a espécie em questão.

A sobrevivência dessa espécie foi observada durante três meses, em laboratório, partindo-se de 10 exemplares adultos.

Ateuchus mutilatus, conforme nosso estudos, sobreviveu em média três meses, de acordo com os resultados da tabela VIII.

2) Associações em criadouros e armadilhas: Ačeuchus mutilatus apresentou-se isoladamente num total de 35 vezes, sendo $24 \mathrm{em}$ criadouros (sete em fezes de bovinos, $13 \mathrm{em}$ fezes de eqüinos, quatro em fezes de suinos, não aparecendo em fezes de ovinos] e 11 vezes em armadilhas. Associou-se com uma espécie 31 vezes, com duas espécies três vezes e com quatro espécies uma vez. (Tabela IX).

3) Nidificação e desenvolvimento de ovo a adulto: Harold (1868) descreveu a espécie e sua localidade geográfica, como sendo Brasil (Rio de Janeiro: Nova Friburgo). PESSOA \& LANE (1941) encontraram Ateuchus mutilatus no Rio de Janeiro (Nova Friburgo, Petrópolis, Serra de Bocaina e Serra de Macaé e em São Paulo (Campos do Jordão). Já LANGE (1947) encontrou Choeridium mutilatum em excrementos de bovinos, eqüinos e humanos no Estado do araná (Araucária, Campo Largo, Curitiba, Florestal, Imbuial, Monte Alegre, Piraquara e Ponta Grossa).

Assiln como Ateuchus apicatus Harold, 1867, Ateuchus mutilatus apresenta o mesmo comportamento de nidificação, colocando os ovos diretamente na massa fecal no fundo cego do buraco. HALFFTER \& MATTHEWS (1966). Este buraco apresentava uma porção perpendicular de $10 \mathrm{~m}$ de profundidade, quando, então, fazia uma curvatura, tomando uma posição horizontal, perpendicular à superfície e prolongando-se mais de $10 \mathrm{~cm}$, ter minando em fundo cego. A largura do buraco é de $1,5 \mathrm{~cm}$ em toda a extensão. Apenas $5 \mathrm{~cm}$ abaixo da superfície ficam livres de fezes; praticamente, toda a tubulação está preenchida por fezes. (Figura 5)

O número de bolas de fezes variou de quatro a cinco, essas de forma oval com $2 \mathrm{~cm}$ de comprimento $X 1,5 \mathrm{~cm}$ de largura. No 


\section{TABELA VII}

Distribuição mensal das espécies de copríneos capturados durante a noite, em Mandirituba, PR, no período de outubro de 1983 a outubro de 1984.

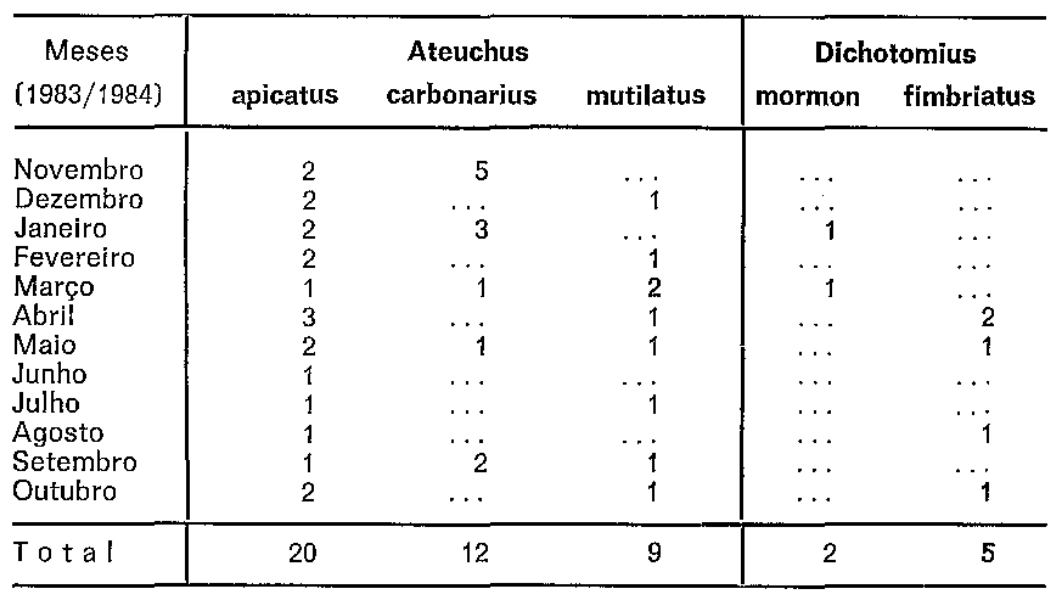

\section{TABELA VIII}

Sobrevivência em dias, dos copríneos adultos de Ateuchus apīcatus Harold, 1867, de Ateuchus mutilatus Harold, 1867 e de Dichotomius fimbriatus Harold, 1869, à temperatura máxima de $23,6^{\circ} \mathrm{C}$ e mínima de $12,4^{\circ} \mathrm{C}$, em Curitiba, $\mathrm{PR}$ no períado de outubro de 1983 a outubro de 1984 .

\begin{tabular}{crrccc}
\hline \multirow{2}{*}{ Data } & \multicolumn{2}{c}{ Temperatura } \\
& Máx. & Mín. & A. apicatus & $\begin{array}{c}\text { Copríneos Vivos } \\
\text { A. mutilatus }\end{array}$ & D. fimbriatus \\
\hline $23-05-84$ & 23,1 & 12,2 & 10 & 10 & 10 \\
$07-06-84$ & 21,2 & 8,9 & 10 & 10 & 10 \\
$22-06-84$ & 21,2 & 8,9 & 8 & 10 & 10 \\
$07-07-84$ & 20,2 & 8,5 & 6 & 8 & 8 \\
$22-07-84$ & 20,2 & 8,6 & 1 & 4 & 5 \\
$07-08-84$ & 17,9 & 8,2 & $\ldots$ & 2 & 3 \\
$22-08-84$ & 17,9 & 8,2 & $\ldots$ & 2 & 2 \\
\hline
\end{tabular}




\section{TABELA IX}

Ocorrência de Ateuchus mutilatus Harold, 1867, adultos, isolados e sintópicos, em Mandirituba, PR, em criadouros com fezes de bovinos, de eqüinos, de ovinos e de suínos e em armadilhas, no período de outubro de 1983 a outubro de 1884.

\begin{tabular}{|c|c|c|c|c|c|c|}
\hline Coleópteros & & $\frac{8}{8}$ & 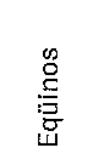 & $\stackrel{\overbrace{}}{\stackrel{2}{8}}$ & $\begin{array}{l}\stackrel{8}{\circ} \\
\stackrel{\Xi}{5} \\
\overline{0}\end{array}$ & 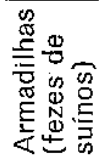 \\
\hline $\begin{array}{l}\text { Isolados } \\
\text { Ateuchus mutilatus (A.m.) }\end{array}$ & 35 & 7 & 13 & $\ldots$ & 4 & 11 \\
\hline$\%$ de preferência & & 20,00 & 37,14 & . & 11,43 & 31,43 \\
\hline \multicolumn{7}{|l|}{ Sintópicos } \\
\hline A. $m . x$ Canthidium breve ( $C . b)$. & 8 & $\cdots$ & 2 & & 6 & . \\
\hline A.m $\times$ Canthidium dispar (C.d.) & 3 & $\ldots$ & $\cdots$ & $\ldots$ & 2 & 1 \\
\hline A.m. $x$ Dichotomius fimbriatus (D.f.) & 6 & & 2 & $\ldots$ & 2 & 1 \\
\hline A.m. $x$ Dichotomius mormon [D.m.] & 3 & . & 2 & $\ldots$ & 1 & . \\
\hline A.m. $x$ Onthophagus hirculus (O.h.) & 3 & 1 & 1 & & . & 1 \\
\hline A.m. x Uroxy dilaticollis (U.d. $)$ & 8 & 1 & 1 & $\ldots$ & 4 & 2 \\
\hline Am. $x$ D.f. $x$ U.d. & 1 & .. & $\ldots$ & $\ldots$ & .. & 1 \\
\hline A.m. $\times$ D.m. $\times$ U.d. & $i$ & . & $\cdots$ & .. & 1 & . \\
\hline A.m. $\times$ U.a. ${ }^{*} \times U_{u} d_{n}$ & 1 & . & $\ldots$ & 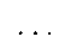 & . & 1 \\
\hline A.m $\times$ A.a. ${ }^{*} \times$ A.c. $\times$ O.h. $\times$ U.a. & 1 & 1 & $\ldots$ & $\ldots$ & $\ldots$ & . \\
\hline$\%$ de $\stackrel{\Sigma}{\mathbf{p}}=$ & 35 & $\begin{array}{r}3 \\
8,77\end{array}$ & $\begin{array}{r}9 \\
25,71\end{array}$ & & $\begin{array}{r}16 \\
45,71\end{array}$ & $20,00^{7}$ \\
\hline
\end{tabular}

* U.a. (Uroxys angulicollis); A.a. (Ateuchus apicatus); A.c. (Ateuchus carbonarius). 


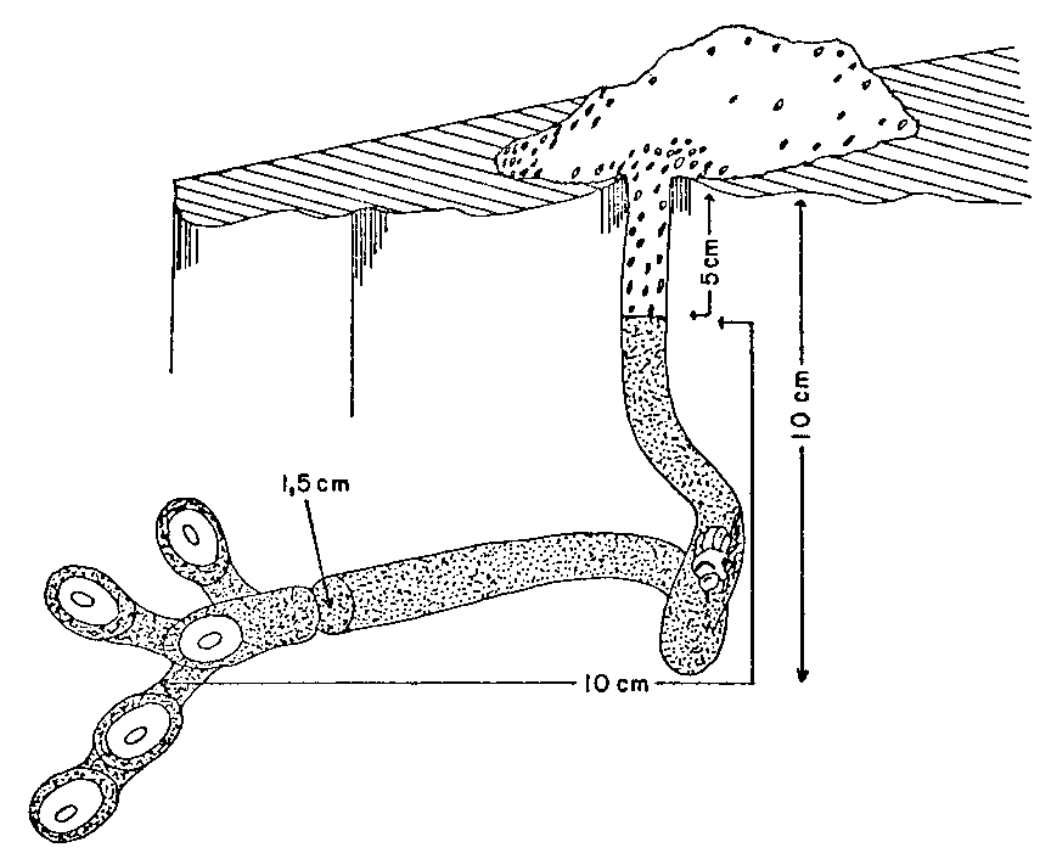

Fig. 5: Corte esquemático da nidificação de Ateuchus mutilatus Harold, 1867. 
interior dessas bolas está a câmara do ovo; dentro dessa encontramos o ovo solto. (Figura 6).

Mensuramos 10 câmaras de Ateuchus mutilatus, apresentando os seguites dados estatísticos: Média $(\bar{x})=0,510$; Desvio padrão (s) $=0,077$; Erro padrão $(s \bar{x}$ ] $=0,024$; Mínimo (mín.) $=0,400$; Máximo (máx.) $=0,600$; Intervalo de Confiança para a média: $(0,454 \leq \mu \leqslant 0,565)=95 \%$.

OVO: De forma perfeitamente oval, de cor branco-leitosa. Mensuramos 20 ovos e apresentamos os seguintes dados estatisticos:

Comprimento: Média $\overline{(x)}=1,752 ;$ Desvio padrăo $(\mathrm{s})=$ 0,078; Erro padrão $[\overline{s x}]=0,017$; Mínimo (mín.) $=1,600$; Má ximo (máx) $=1,840$; Intervalo de Confiança para a média: $\{1,715 \leqslant \mu \leq 1,788)=95 \%$.

Largura: Média $(\bar{x})=1,086$; Desvio padrão (s) $=0,090$; Erro padrão ( $s \bar{x})=0,020$; Mínimo (mín.) $=0,960$; Máximo (máx.) $=1,240$; Intervalo de Confiança para a média: $(1,043 \leq \mu \leqslant 1,128)$ $=95 \%$.

Estudamos o período de desenvolvimento, em dias, de Ateuchus mutilatus em 32 ovos, apresentou esses resultados: Média $^{-}(x)=15,062$; Desvio padrão $(s)=6,786$; Erro padrăo $(\overline{s x})=1,199 ;$ Mínimo (mín.) $=7,000$; Máximo (máx.) $=$ 28,000 ; Intervalo de Confiança para a média: $\{12,615 \leq \mu \leqslant$ $17,509)=95 \%$.

LARVA DE PRIMEIRO ESTÁDIO: Após 15 dias em média, nasce uma larva de primeiro estádio, medindo $0,8 \mathrm{~cm}$ de comprimento, em forma de " $\mathrm{C}$ ", cabeça esbranquiçada e abdômen de cor escura. A porção posterior fica aderida ao fundo da câmara e a porção cefálica, em movimentos circulares, alimentase ativamente. (Figura 7).

O tempo de desenvolvimento das larvas de primeiro a ter. ceiro estádio, por nós mensurados, foi o seguinte: Média $(\bar{x}]$ $=104,600$; Desvio apdrăo $(\mathrm{s})=3,660$; Erro padrão $(\mathrm{s} \overline{\mathrm{x}})=0,945$; Mínimo (mín.) $=100,000$; Máximo (máx.) $=114,000$; Intervalo de Confiança para a média: $(102,572 \leq \mu \leq 106,627)=95 \%$.

A larva de primeiro estádio, em média de 104 dias, torna-se LARVA DE TERCEIRO ESTÁDIO, passando a fabricar o casulo. Este, de forma oval, com base fixa ao substrato das fezes, pos- 


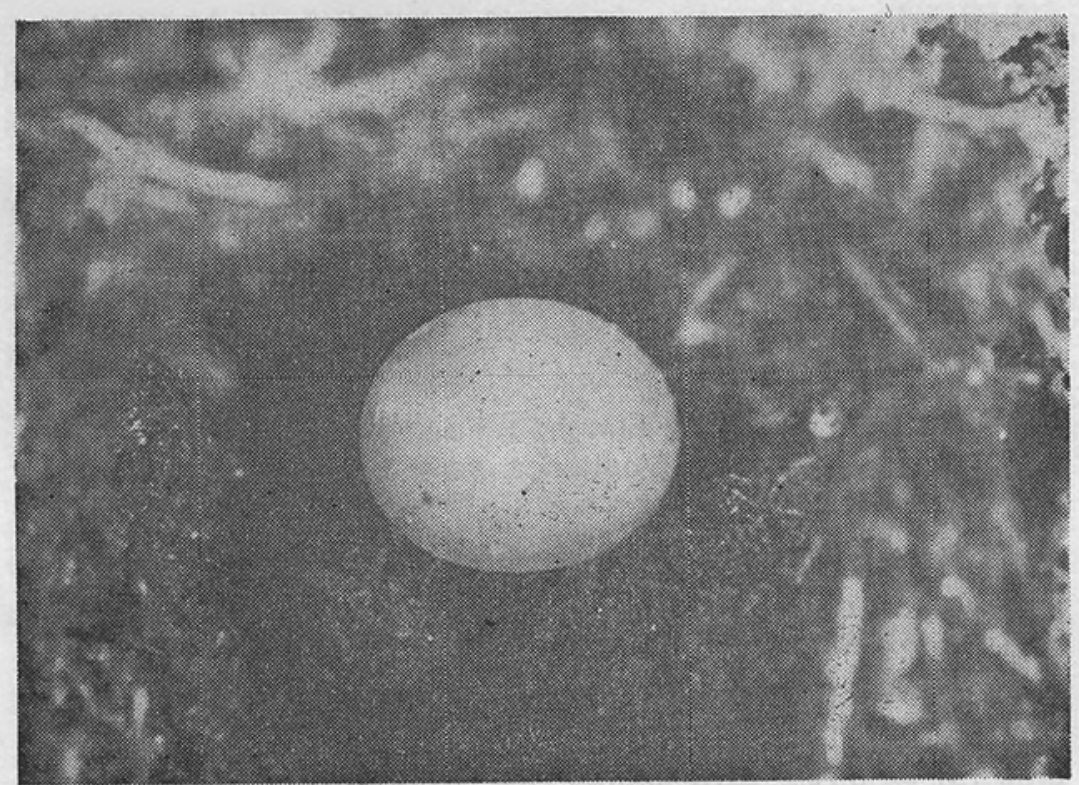

Fig. 6: Câmara com ovo de Ateuchus mutilatus Harold, 1867.

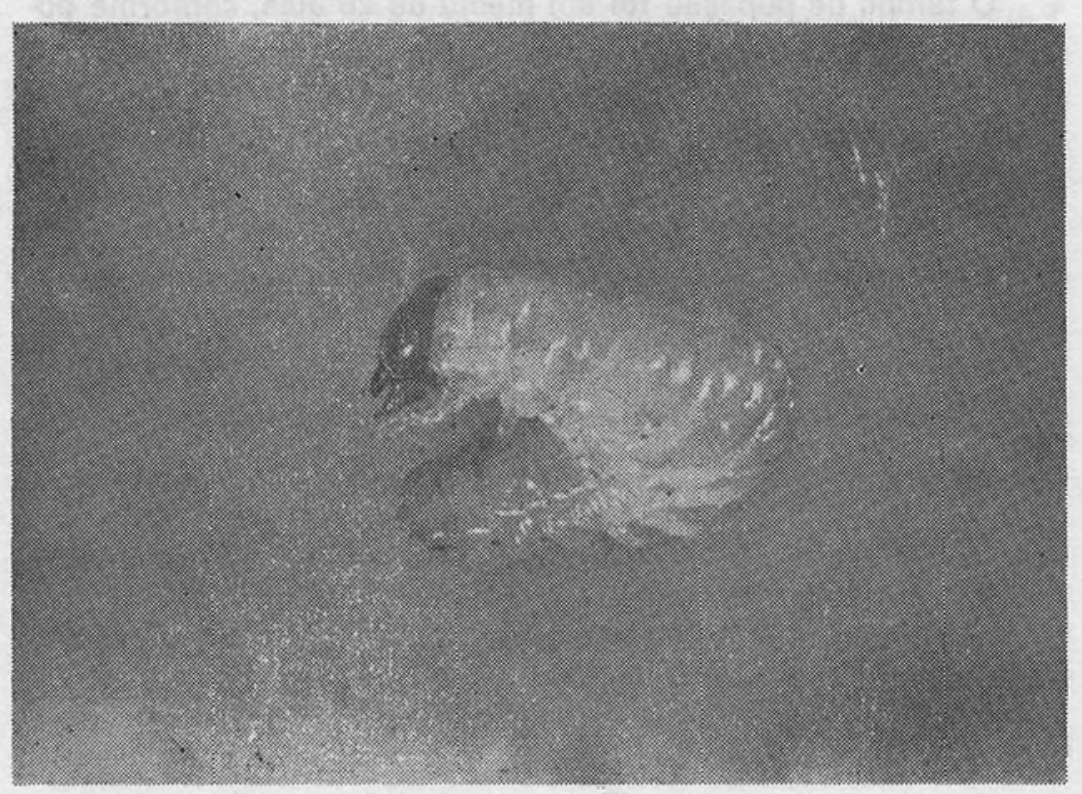

Fig. 7: Larva de primeiro estádio de Ateuchus mutilatus Harold, 1867. 
sui superfície externa rugosa e a interna, lisa, de cor marromescura. (Figura 9).

Mensuramos cinco casulos, com os seguintes resultados:

Comprimento: Média $\overline{(x)}=1,164$; Desvio padrão (s) $=$ 0,061; Erro padräo $(\overline{s x})=0,027$; Mínimo (mín.) $=1,100$; Máximo (máx.) $=1,250$; Intervalo de Confiança para a média: $[1,088$ $\leq \mu \leq 1,239)=95 \%$.

Largura: Média $(\bar{x})=0,964$; Desvio padrão $(s)=0,041$; Erro padrão $(\overline{s x})=0,018$; Mínimo (mín.) $=0,900$; Máximo (máx.) $=1,000 ;$ Intervalo de Vonfiança para a média: $(0,912 \leq \mu \leq$ $1,015)=95 \%$.

A larva de terceiro estádio é de cor esbranquiçada, sendo a cabeça amarelada, a forma do corpo tipo " $\mathrm{C}$ ". (Figura 8). Apresenta tórax e abdômen cobertos de cerdas. Mede aproximadamente $3,7 \mathrm{~cm}$. Mensuramos cinco larvas de terceiro estádio com os seguintes resultados: Média $(\bar{x})=3,704$; Desvio padrão $(s)=0,295$; Erro padrão $\bar{s} \mathrm{~s})=0,132 ;$ Mínimo (mín.) $=$ 3,300; Máximo (máx.) $=4,000$; Intervalo de Confiança para a média: $(3,337 \leq \mu \leq 4,070=95 \%$.

O tempo de pupação foi em média de 26 dias, conforme pode-se verificar pelos resultados: Média $[\bar{x}]=26,125$; Desvio padrão (s) $=4,323$; Erro padrão $(s \times)=1,528$; Mínimo [mín.] $=$ 21,000; Máximo (máx.) = 35,000; Intervalo de Confiança para a média: $(22,510 \leq \mu \leq 29,739)=95 \%$.

A PUPA evolui dentro do mesmo casula da larva de tercei. ro estádio, que se abre pela ação do próprio inseto adulto. (Figura 9).

Mensuramos 10 exemplares adultos (machos e fêmeas) de Ateuchus mutilatus, obtendo-se os seguintes resultados:

\section{MACHOS:}

Comprimento: Média $[\bar{x}]=13,068$; Desvio padrão $(s)=$ 1,233; Erro padrão $(s \bar{x})=0,390$; Mínimo $($ mín. $)=11,160$; Máximo (máx.) = 14,760; Intervalo de Confiança para a média: $(12,185 \leq \mu \leq 13,950)=95 \%$.

\section{FÊMEAS:}

Comprimento: Média $(\bar{x})=12,510$; Desvio padrão $(s)=$ 


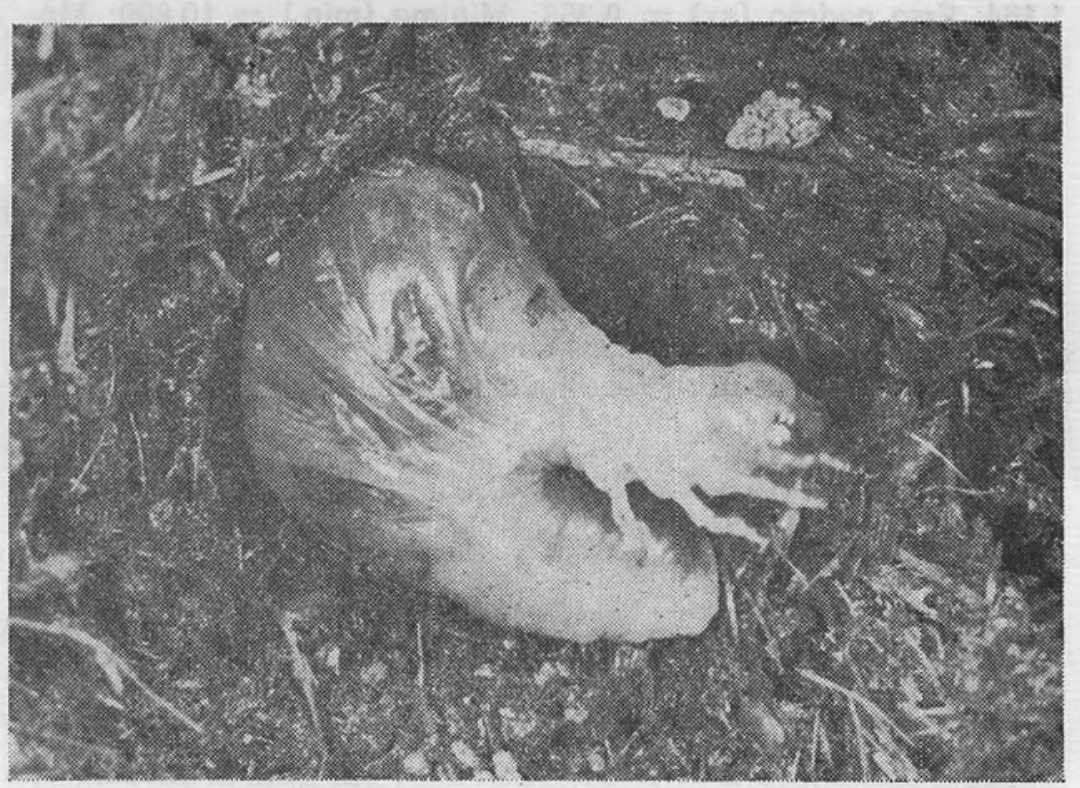

Fig. 8: Larva de terceiro estádio de Ateuchus mutilatus Harold, 1867.

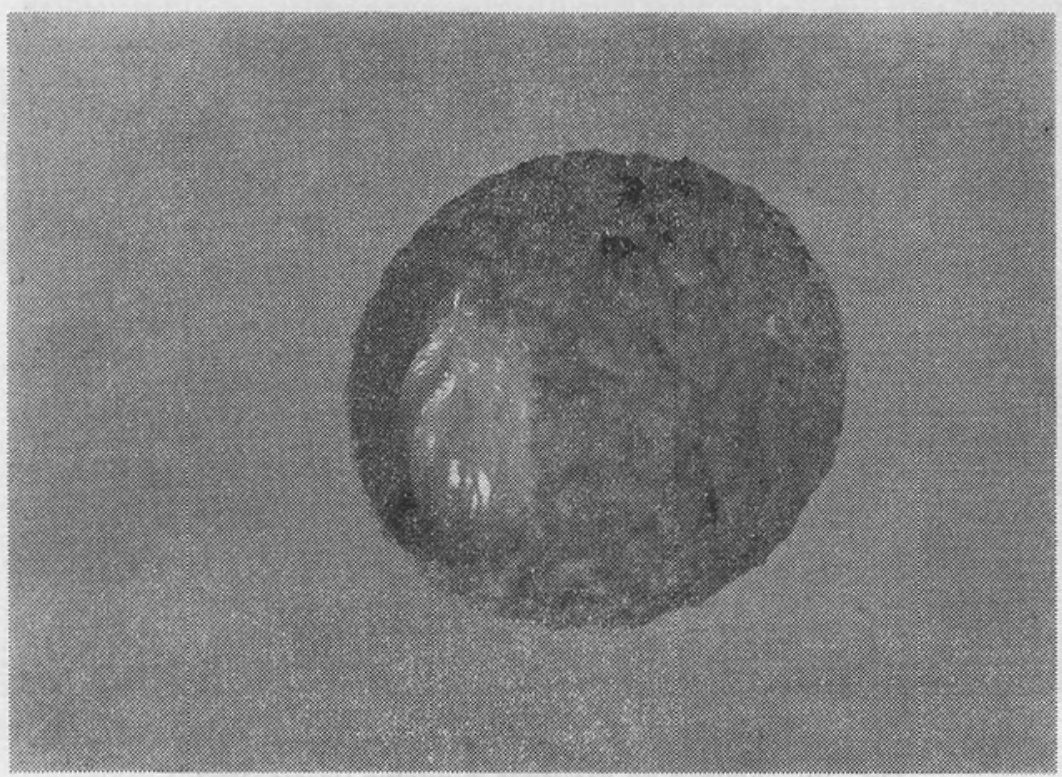

Fig. 9: Casulo com pupa de Ateuchus mutilatus Harold, 1867. 
1,164; Erro padrão $(s \bar{x})=0,368$; Mínimo (mín.) $=10,800$; Máximo (máx.) $=14,400$; Intervalo de Confiança para a média: $(11,677 \leq \mu \leq 13,342)=95 \%$.

Largura: Média $(\bar{x})=7,884$; Desvio padrão $(s)=0,913$; Erro padrão $(\overline{s x})=0,288$; Mínimo (mín.) =6,300; Máximo (máx.) $=9,000$; Intervalo de Confiança para a média: $(7,230 \leq \mu \leq$ $8,537)=95 \%$.

As dimensões dos adultos (figura 10) por nós pesquisados, estão de acordo com os resultados apresentados por HAROLD (1868).
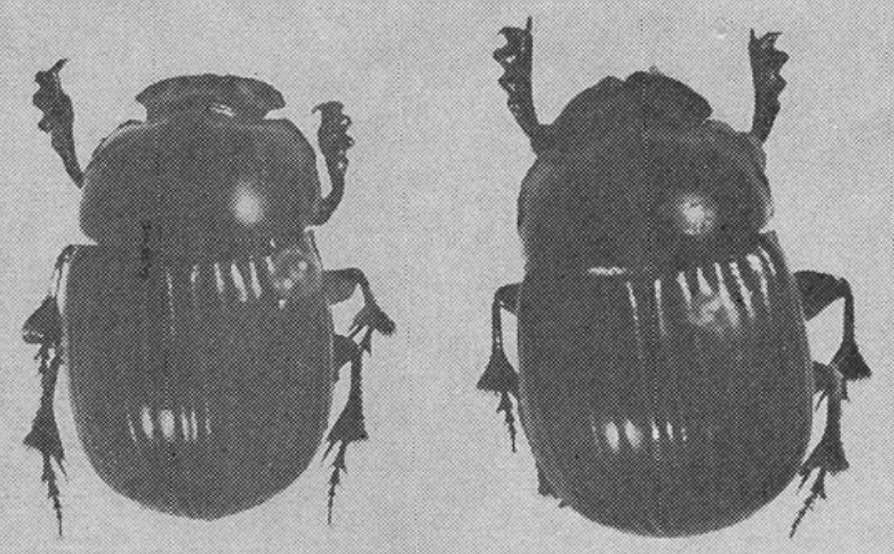

a

b

Fig. 10: Adultos de Ateuchus mutilatus Harold, 1867
a. macho
b. fêmea 


\section{CONCLUSÕES}

1. Dos 4869 escarabeídeos capturados durante todo o ano, 323 exemplares eram de Ateuchus mutilatus, com um percentual de $6,60 \%$.

2. Ateuchus mutilatus foi encontrado nidificando em excrementos de bovinos, eqüinos e suínos, não sendo encontrado nas fezes de ovinos. Apresentou uma nítida preferência pelas fezes de eqüinos $(75,2 \%)$.

3. A sua atividade foi noturna.

4. A sobrevivência foi de aproximadamente 90 dias.

5. Apresentou preferência pelas armadilhas parcialmente sombreadas.

6. Nas associaçónes apresentou-se isoladamente num total de 35 vezes, sendo 24 em criadouros e 11 em armadilhas. Associou-se a uma espécie 31 vezes, a duas espécies três vezes e a quatro espécies uma vez.

7. O período de desenvolvimento da fase de ovo à de adulto de Ateuchus mutilatus foi, em média, de 145 dias.

8. O ovo, a larva e a pupa de Ateuchus mutilatus foram descritos pela primeira vez.

\section{RESUMO}

A abundância relativa de Ateuchus mutilatus Harold, 1867 encontrada em armadilhas e criadouros fol de $6,60 \%$. breadas.

Essa espécie predominou em armadilhas parcialmente som-

Foi abordado pela primeira vez, experimentalmente, o estudo dos aspectos biológicos e morfológicos dessa espécie.

O período de desenvolvimento da fase de ovo à adulto foi de aproximadamente 145 dias.

A sobrevivência do adulto de Ateuchus mutilatus foi cerca de 90 dias.

A atividade dessa espécie mostrou-se de hábito noturno.

PALAVRAS CHAVE: Ateuchus mutilatus Harold, 1867; Coleoptera; Scarabaeidae; Scarabaeinae; Biologia. 


\section{SUMMARY}

The relative numbers of Ateuchus mutilatus Harold, 1867 found in traps and breeding pens was of $6.60 \%$.

The large occurence of this specie was achieved in partially shaded traps.

For the first time, an experimental approach was used in the study of the biological and morphological elements of Ateuchus mutilatus.

The period of development from the egg phase until the adult stage of Ateuchus mutilatus was found to average of 145 days.

While observing the life-span of adults of Ateuchus mutilatus we ascertained that this specie survived for some three months.

The activity of this specie was nocturnal.

KEY WORDS: Ateuchus mutilatus Harold, 1867; Coleoptera; Scarabaeidae; Scarabaeinae; Biology.

\section{RESUME}

Ateuchus mutilatus Harold, 1867 a été trouvé en abondance $(6,60 \%)$ dans les pièges et dans les locaux de développement.

Cette espèce a prédominé dans les pièges partialement l'ombre.

Les auteurs ont étudié pour la première fois les aspects biologiques et morphologiques de cette espèce.

En moyenne la période de développement de l'oeuf à l'adulte de Ateuchus muxiliatus a été de 145 jours.

La survie de l'adulte a été presque de 90 jours.

L'activité de cette espèce a été nocturne.

MOTS CLÉS: Ateuchus mutilatus Harold, 1867; Coleoptera; Scarabaeidae; Scarabaeinae; Biologie.

BIBLIOGRAFIA

1 - HALFFTER, G. \& MATTHEWS, E.G. The Natural History of dung beetles of the family Scarabaeinae (Col. Scarab.). Folia Entomol. Mex., México, (12-14):1-312, 1966. 
2 - HAROLD, E. von. Die Arten der Gattung Choeridium. Coleopt. Hefte, Munique, 4:32-76, 1868.

3 -- LANGE, R.B. Ensaio da Zoogeografia dos Scarabaeidae do Paraná com algumas notas eto-ecológicas. Arq. Mus. Parana., Curitiba, 6: $305-315,1947$.

4 - PESSOA, S.B. \& LANE, F. Coleópteros de interesse médico-legal; ensaio monográfico sobre a familia Scarabaeidae de São Paulo e regiōes vizinhas. Arq. Zool., São Paulo, 2:389-504, 1941. 